\title{
Incitación para recuperar el futuro Una lectura de la Razón Esperanzada de Ernst Bloch
}

\author{
Adrián Gurza Lavalle*
}

Resumo: Este texto visa estimular o resgate e a releitura da obra do filósofo alemão, contemporânea e atual, porém paradoxalmente esquecida. Para isso, percorre em primeiro lugar as principais características do discurso blochiano, a recepção acadêmica e política decorrente delas, e, em seguida, as categorias centrais que sustentam sua Filosofia da Esperança. Baseado na diferença blochiana entre utopia e Esperança, o artigo encerra discutindo a pertinência da crítica do filósofo da Esperança ao Leste Europeu e sugerindo algumas lições para se pensar a crise da utopia socialista.

Palavras-chave: utopia - princípio esperança - marxismo - socialismo - Leste Europeu.

No es tan fácil sostener la emoción utópica, a sabiendas de que no hay reinos-de-dios-sobre-la-tierra.

Carlos Monsivais

La conciencia revolucionaria lleva inherente la melancolía, es decir, la

tristeza por el fracaso de un proyecto pese a todo irrenunciable.

Jürgen Habermas

No cabe duda de que la gran maestra de la sátira, por encima de cualquier pluma o ingenio, es la historia; ella es artífice de intrincados dramas, venganzas, castigos tardíos y eternas injusticias, sólo que en su caso y a diferencia de las expresiones artísticas literarias o dramáticas, la trama se juega en el escenario

\footnotetext{
* Doutorando do Departamento de Ciência Política - FFLCH-USP, bolsista CNPQ e professor da UNAM (Universidade Nacional Autônoma do México) e da UIA (Universidade Interamericana).
} 
de la vida misma en su forma de totalidad omnicomprensiva. Después de todo y a despecho de las más notables agudezas del pensamiento posmoderno, la distancia entre vida y fábula, entre historia y relato o entre filosofia y literatura, es tan cruda y radical como la verdad de la muerte y del dolor en la carne de los vivos. Aquello que parece una obviedad no lo es tanto, ¿dónde radica la verdad de las ideas y cuál es el daño de la palabra traicionada?: ¿acaso Galileo Galilei pensó que su célebre retracción atenuada -epure se muove- se convertiría en paradigma diferenciador de los deberes del científico como hombre común y los deberes del científico en tanto que hombre de ciencia? Ironía, aquél que pensó salvar a la ciencia para la posteridad, también terminó por sintetizar simbólicamente al sepulturero de una ética científica para una humanidad urgida de controlar límites ${ }^{1}$. Y la ironía pródigamente obsequiada por esta maestra de la sátira que es la história se multiplica sin cesar: en nombre del capitalismo que dejó sin cumplir buena parte de las esplendorosas promesas de modernidad anunciadas por el Espíritu Absoluto, se invoca y ultraja la obra de Hegel para propalar la vieja nueva del fin de la historia bajo absolutización de una forma estatal única ${ }^{2}$. El listado puede ser interminable cuando se trata del paciente oficio de reconstruir la saturación (satura, sátira) de elementos a través de los cuales la historia ejerce su arrasadora crítica cobrando la verdad de las palabras, pero interesa rescatar, muy a propósito de la interrogante por el locus de la verdad en el universo de la palabra, el sarcasmo histórico que envolvió y continua envolviéndo el pensamiento de una de las mentes singularmente lúcidas del presente siglo, cuya obra suele ser escasamente conocida en relación a su magnitud e importancia o, en todo caso, menospreciada por su peculiar forma de habitar el mundo de la palabra. Se trata, en efecto, de Ernst Bloch y del largo filosofar de su Razón Esperanzada (1885-1977)3. El transcurso de estas páginas no pretende ofrecer otra cosa sino una incitación para bracear contra el olvido en que se encuentra su obra y para sumergirse en la calidez de un pensamiento, de una filosofía esperanzada, cuya actualidad nos es revelada en más de una forma por las ironías de la historia. 


\section{Una Acogida Gélida para un Marxismo Cálido}

Ernst Bloch comparte con Antonio Gramsci, además de con la Escuela de Frankfurt, el mismo obscuro escenario histórico en el hilvanarar ideas para la configuración de su pensamiento; no les tocaron tiempos de éxito para las promesas de futuro constitutivas del gran pensamiento filosófico moderno, condensadas insuperablemente en el Espíritu Absoluto hegeliano. La cuenta es amarga: dos guerras mundiales en las que, además de la vida de millones de personas, se echaron por tierra los ideales del internacionalismo proletario; la derrota de los partidos comunistas en toda la Europa Occidental y, por si fuera poco, el expansivo imperialismo soviético no menos voraz que el del capitalismo y la clausura autoritaria del proyecto socialista en manos de las nomenclaturas comunistas. Ambos, Bloch y Gramsci, son pensadores de la derrota e incluso desde la derrota, comprometidos intelectual y vitalmente con la transformación revolucionaria hacia el socialismo, de lo que quedó hueya a través de sus accidentadas biografías y de sendas obras teóricas que ensancharon y contribuyeron a mantener la vitalidad del marxismo, sentenciado a la momificación en los mausoleos de los diversos dogmatismos imperantes. En medio de la derrota y desde la cárcel, Gramsci desarrollaria una teoría política de la revolución frente a un Estado ampliado que habia comenzado a entreverarse con la sociedad ( $c f r$. Gramsci 14); frente a la derrota, desde el exilio o en medio de la desilusión y la censura, a su regreso a la Alemania del bloque comunista, Bloch honraria la idiosincracia del pensamiento germano y desarrollaria una filosofia de La Esperanza y del futuro o, para decirlo con Bloch, emprenderia “(...) con especial atención el ensayo de llevar filosofía a la esperanza (...)"4. Pero no es en la esperanza fraguada en el molde de la desilusión y la derrota donde estriba la ironía biográfica de Bloch, después de todo la complejidad de la vida es un flujo irrefrenable de alteraciones y compensaciones. Es la relación entre el sentido de la obra de Bloch, la recepción que de ella se ha tenido y el devenir de los acontecimientos que marcaron éste siglo, lo que hace una sátira, no de la biografía de Bloch, sino de nuestra propia historia.

Por decir lo menos, la recepción académica y política de la obra del filósofo esperanzado de Tübingen ha sido poco afortunada. En el primer caso, son tres las cualidades o características del pensamiento de Bloch que permiten comprender la desatención de que ha sido objeto en el campo del quehacer inte- 
lectual, a saber, su peculiar estilo en el uso de la palabra, ajeno a la formalidad de un rigorismo academicista; su fuerza discursiva casi religiosa, de un sabor a mesianismo cristiano reforzado por sus trabajos en esta área; por último, la índole metafísica confesa de las preocupaciones que vertebran toda su obra. El peculiar estilo del discurso de Bloch, de prosa emotiva, construcción alegórica e intencionalmente plurívoco, ha provocado la reticencia de un cientificismo que juzga este esfuerzo poco riguroso para ser filosofía y muy próximo al ensayismo literario para ser considerado con seriedad científica. Contemporáneo de Brecht, de Benjamin y en general de la crítica a la cosificación de los conceptos desarrollada por la Escuela de Frankfurt, Bloch era partícipe de lo que puede ser denominado clima experimental en Alemania, que por supuesto no resulta ajeno a las enormes repercusiones de la obra de un autor como Nietzsche; sin embargo, a respecto del estilo resultaria considerablemente más significativa la sólida formación cultural de Bloch en el contexto del expresionismo literario en los albores del siglo ( $c f r$. Opolka 18, pp. 82-90; Zecchi 23, pp. 217-239), si no fuera porque estas dos consideraciones hacen de la singularidad de la prosa blochiana una cuestión meramente estilística. En realidad, contenido y forma resultan internamente inescindibles en la odisea blochiana. La palabra no puede ser extraña a su contenido, siempre cargado de intenciones; aún mas, en tanto que para Bloch ser y realidad no coinciden, la palabra no tiene contenido vital alguno garantizado, debe ser creída, asumida y habitada para ser realizada: "Algo corrector, enriquecedor, iluminador del mundo, desde sí mismo, sólo puede proceder de un punto de vista de la conciencia conquistado científicamente: de un punto de vista, eso sí, todavía habitado" (Bloch 7, p. 448).

En estrecha relación con su instigante y seductora forma de escribir se encuentra su vínculo cognitivo y emotivo con el mesianismo cristiano como una de las fuentes primordiales para la elaboración de la problemática de la esperanza; vínculo con frecuencia mal entendido cuando se le atribuyen pretensiones mesiánicas al propio filósofo. En tiempos obscuros y de porvenir dudoso, en los que el Espíritu Absoluto se habia convertido en un fantasma ${ }^{5}$, Bloch se empeñó en la tarea de abrir campo a La Esperanza y para ello fue necesario desarrollar una fenomenología que, por supuesto, encontró en la religión el principal santuario de la espera convencida de un mundo mejor; espera, por cierto, no siempre contemplativa y difícilmente reductible a un efecto perverso de pura y simple enajenación -"opio de los pueblos"- (Bloch 8, pp. 78-82). 
Para Bloch, los contenidos anticipadores y transformadores del cristianismo, condensados de forma espléndida en el mesianismo, son una manifestación de la continuidad de la esperanza como dimensión ontológicamente constitutiva del hombre y del carácter trascendente-sin-trascendencia de la utopía (Bloch 5, pp. 160 y ss.). De este modo y más próximo del proceder de Hegel que del de $\mathrm{Marx}^{6}$, es posible para Bloch establecer una genealogía remota que hace del marxismo la expresión más avanzada de una esperanza ancestral: "Aún inaudita, la obra subterranea de la revolución aguarda su obra, ya iniciada en el curso correcto; los hermanos del valle, los herejes, los vaudois, los albigeois, el abad Joachim de Calabrese, los hermanos de la buena voluntad, de la vida comunitaria, del total discernimiento, del libre espíritu, Eckhart, los husitas, Münzer y los bautistas, Sebastian Franck, los iluministas, Rousseau y la mística humanista de Kant, Weitling, Baader, Tolstoi, todos ellos se unen y el consciente de esta fantástica tradición resuena estruendoso de nuevo contra el miedo, el Estado, la incredulidad y contra los altos poderes deshumanos (...) De esta forma se unen finalmente el marxismo y el sueño de lo incondicional en el mismo paso y en la misma cruzada (...)" ".

A este orden de preocupaciones blochianas se debe el que, muchas veces en demérito una mejor comprensión, su obra haya resultado cristiana para los marxistas y marxista para los cristianos; no obstante, el desafio de llevar la filosofia a La Esperanza suponía, precisamente, la superación de su manifestación religiosa y el desarrollo de una nueva filosofia en la que la espera inmemorial por lo nuevo pudiera recibir un tratamiento sistemático y riguroso. Sólo la filosofía para dar cuenta de que, más alla de todo psicologismo -en el que la esperanza se torna un estado de ánimo o una manifestación de la estructura psíquica-, lo específicamente humano de la realidad del hombre estriba en que su construcción está hecha desde el futuro, pues "El ser que condiciona la conciencia, como la conciencia que elabora el ser, se entienden, en último término, sólo en aquello desde lo que proceden y hacia lo que tienden. La esencia no es la preteridad; por el contrario, la esencia del mundo está en el frente" (Bloch 5, p. XXVIII). Si la esencia del mundo está en el frente, cómo pensar la realidad a partir de categorías de la materia, de lo real, de lo posible y del ser construidas sobre la base de un determinismo del pasado. Se evidencia así la necesidad de avanzar un nuevo pensamiento, específicamente una nueva metafísica, edificada como una exploración universal de la indeterminación 
en lo parcialmente determinado ${ }^{8}$, es decir, desarrollada como una filosofía del futuro. "De lo anticipante hay que ganar conocimiento sobre la base, por tanto, de una ontología de lo que todavía-no-es" (Bloch 5, p. XXII). El carácter abiertamente metafísico de los esfuerzos blochianos, en contra de una ya bicentenaria corrida de las ciencias y hasta de la filosofia por abandonar los reinos de este saber especulativo, hace que aún hoy la obra del filósofo de Tübingen pase desapercibida incluso para quienes intentan rearmar su pensamiento para vislumbar los caminos de superación de las desventuras de nuestro presente9. Sin duda alguna y en contra la indeferencia metafísica de los tiempos, saciada de vacio, la excepcional mixtura de elementos poco abundantes dentro de la tradición marxista hace de la obra de Bloch un caso verdaderamente notable y vital de marxismo cálido ${ }^{10}$.

En cuanto a su recepción política, el pensamiento de Bloch se encontraba situado a fuego cruzado en una pugna permanente entre el revisionismo de posguerra, que progresivamente relegaba a un plano insignificante la posibilidad de una transformación a fondo de la sociedad y descartaba la problemática de la revolución, y el dogmatismo comunista, que bajo una formalización cuasi canónica del marxismo a la Diamat aniquiló toda apropiación fructífera de este legado teórico y toda manifestación crítica de pensamiento independiente. En este campo, Bloch fue objeto de ataques por ambos bandos entre epítetos de ingenuidad revolucionaria o de idealismo claudicante ${ }^{11}$. La escasa asimilación real de su pensamiento se prolongó por el hecho de que al radicarse en la Alemania Democrática, al finalizar la segunda gran guerra, su obra fue deficientemente difundida del lado de la Europa occidental y amenazadoramente subversiva dentro del Bloque, por lo que de este lado, el oriental, no se hizo esperar su descalificación por sus atributos supuestamente antirrevolucionarios. Como será visto más adelante, Bloch advertía ya desde entonces, apartir de su peculiar preocupación por la utopía, sobre los peligros que implicaban la política adoptada en la Europa del Este. Al paso de las décadas y casi dos lustros después de la vertiginosa debacle del bloque socialista, resulta difícil no recordar a Bloch como heraldo de las consecuencias destructivas y perversas de la falta de espacio para la Razón Esperanzada y la asfixia represiva de todo querer transformador: "Pero el hecho -afirma Bloch- de que nos encontramos en un terreno edificable y no en un paraíso, es excesivamente infravalorado por nuestros administradores (que sin más constituyen un obstáculo para la 
construcción)" (Zecchi 23, p. 48, apud. Bloch 12).

Debido a su prédica humana y cuestionadora, siempre molesta para el verticalismo autoritario del sistema en su necesidad de construir visiones únicas de la realidad, quizá no sea tan sorprendente el vacío creado por la burocracia en torno al pregón del "profeta de los sueños soñados despierto"12; no por ello deja de ser menos irónico el que haya sido precisamente su compromiso con $L a$ Esperanza, en tanto que aún no se hacia del todo evidente la fractura irreparable entre ésta y la utopía socialista encarnada socialismo realmente existente, lo que condenó a Bloch y a su obra al ostracismo durante un largo periodo de su vida. Vale recordar que en vez de permanecer en occidente como lo hicieron los integrantes de la Escuela de Frankfurt, después de exiliado en los Estados Unidos Bloch regresó a Europa en 1947 con la firme decisión de incorporarse a la comunidad intelectual de la Alemania Democrática. En todo caso, tras los acontecimientos consagrados en la imagen metafórica de la caída del muro de Berlín y todo lo que ella trae consigo, el pensamiento del filósofo alemán continua en la desatención, sólo que en este caso se trata de ese enorme vacio de desesperanza e indiferencia dejado por el colapso de los que, para bien o para mal, fueron siempre considerados como bastiones de la utopía socialista. Si en los cuarentas y cincuentas la profundidad y limpieza de sus ideas resultaba estorbosa para quienes se encontraban inmersos en las vicisitudes de la "Realpolitik", en la actualidad, el luto mundial por las utopías -particularmente por el socialismo-marxismo- dictado por intelectos de todos los credos y de todas las orientaciones políticas, ha determinado como superflua e ilusa toda preocupación por el deseo encarnado en querer transformador, por la esperanza $\mathrm{y}$, por supuesto, por la utopía, y por las condiciones sociales que vinculan y dan origen a estos elementos.

A la par de las razones que asisten y desmienten el proclamado fin de las grandes ideologías y de las utopías sociales, el crudo realismo de una nueva ideología conservadora se ha ido expandiendo sin oposición por el mundo. No hay espacio para un querer social diferente ni existen opciones históricas, el futuro es y será nada más que una prolongación del presente. De nueva cuenta se depara el olvido para quien, como Bloch, dedicó su vida a la elaboración de la gravidez del futuro en la determinación de la vida del hombre... y, sin embargo, aún estamos urgidos de respuestas para esa sensación de malestar que campea por el mundo, en la que se intuye que la razón en espera, que la 
esperanza ha sido traicionada, que es necesario reinventar un camino para que la esperanza y la utopía se reencuentren. ¿Acaso puede el hombre vivir sin Metafísica o debe ésta ser expulsada del esfuerzo del concepto para dejarla a su mejor suerte en los refugios de las religiones y de las visiones de mundo? ${ }^{13}$ En el accidentado camino del siglo XX, debiéramos concordar con Bloch: "La necesidad física y metafísica se ha estropeado así el apetito, cerrándosele los caminos para la hartura pendiente, una hartura que no es, desde luego, sólo libresca. La esperanza, y su correlato positivo, la determinabilidad todavía inconclusa sobre la res finita, no aparece así en la historia de las ciencias (...)" (Bloch 5, p. 15).

\section{La Esperanza: una Espera poco Meditada}

Bloch es un digno representante del romanticismo alemán de tinte anticapitalista que permeó los ambientes universitarios y la élite intelectual en las primeras décadas del siglo, ese romanticismo que tiñó la visión poco alagüeña de la modernidad weberiana y el pesimismo de autores como Tönnies y Spengler. En la percepción de este romanticismo Alemania era el valuarte de la cultura universal, de los valores comunitarios -se trata, por supuesto, de la cultura occidental y de los valores agrarios de una Alemania aún tradicional-, mientras que la civilización devastadora del espíritu avanzaba desde los paises capitalistas sobre el resto del mundo. Tal oposición quedó consagrada en el seno de la sociología alemana como el debate entre cultura y civilización, cuyas repercusiones resultan visibles en esa extraña mezcla de crítica revolucionaria con sabor aristocrático propia de la Escuela de Frankfurt. Partícipe del círculo de Weber, Bloch no se adirió a esta vertiente negativa y escéptica hacia los tiempos anunciados por las dos primeras décadas del siglo XX. Inscrito en una perspectiva de izquierda, antes que asumir el curso de la realidad como un destino inapelable, se abocó a reflexionar sobre las condiciones de transformación latentes en el horizonte histórico. Entre otros factores ya mencionados, los escasos indicios positivos de modificación sobre el transcurso del mundo lo llevaron a afianzar su propuesta teórico filosófica en un punto hasta entonces poco meditado: La Esperanza como dimensión humana indispensable para el cambio. 
La filosofía moderna anterior había contado con el supuesto de La Esperanza sin percatarse bien de ello. El imperativo categórico kantiano y su Crítica de la Razón Práctica suponen la existencia de un valor, de un impulso por el que la razón desea comportarse moralmente e ir más allá de los límites de la experiencia sensible, pero el origen del valor y del deseo que lo anhela son un misterio, simplemente existen o metaexisten en el ignoto mundo de los noumenos. El Espíritu Absoluto hegeliano, totalidad histórica absolutamente mediada por si misma, es la racionalidad misma de la historia que se realiza y se justifica por su incontenible e cuasi inmemorial trayecto como historia de la humanidad total. En este caso, la realización del Espíritu por la via de un proceso infatigable de superaciones cuenta a su favor con el supuesto histórico de una Esperanza, que da por hecho un devenir en el mundo de superación positiva; lo que es decir que en Hegel no están explícitamente planteadas las posibilidades de fracaso del Espíritu. Un siglo más tarde, en su Dialéctica Negativa, Theodor Adorno se encargaría de recriminarle a Hegel con amargura precisamente esto, que la filosofía no se habia realizado y que la realidad se habia multiplicado como virulenta negación sin dejar lugar para cualquier posibilidad de conciliación positiva.

Por su parte, Marx reconstruyó el funcionamiento social del capitalismo para dar cuenta de las vías de salida que abrirían paso al socialismo y su teoría de la transformación hizo del proletariado El Sujeto de la transformación histórica, pero con independencia de la posición económica que define objetivamente al proletariado como clase, no parece claro que sólo el determinismo económico de su pobreza sea responsable lo suficiente para volver imperiosamente necesario su deseo de transformación. Paradógicamente, Marx, que puso al hombre al centro de la historia, dió como un supuesto la subjetividad de éste y rescató principalmente la objetividad. Pese a aquella formulación clásica sobre los momentos prerrevolucionarios como aquellos en que se encuentran "dadas las condiciones objetivas y subjetivas", se puede decir que Marx prácticamente resolvió y agotó al hombre en objetividad: el proletariado arribaria irremisiblemente a la conciencia de su ser revolucionario y conquistar su destino por la fuerza de las armas, porque su situación objetiva en el proceso productivo así lo predeterminaba. Resulta claro que la mediación volitiva del sujeto, con los múltiples elementos que esta incorpora, ha sido relativamente pasada por alto ${ }^{14}$. Por supuesto, no vale la pena recordar la proliferación de 
autores y obras para los cuales, dentro de cierta tradición marxista exterminadora de cualquier vestigio metafísico, resultaba un anatema el preguntarse por dimensiones humanas del sujeto tan ajenas al pensamiento científico (y por ello tan peligrosamente matafísicas) como la creencia, la esperanza, la voluntad, el deseo o el sueño.

¿Acaso no es algo más que una casualidad el que tres pensadores de la talla de Kant, Hegel y Marx repitieran tal aparente descuido? La respuesta que parece más pertinente no es compleja: no era requisito indispensable formular La Esperanza para comprender adecuadamente su época a través de sus totalizaciones teóricas o filosóficas. Explicar la voluptuosidad de una razón que no se resigna a permanecer dentro de los estrechos límites de la experiencia posible, cuando la revolución francesa estalló un año después de que Kant escribiera la Crítica de la Razón Práctica, parece una minucia sin sentido resuelta por la evidencia histórica colosal del desplome del ancien régime. En un sentido diferente, también es la historia la que en el caso de Hegel plantea no sólo como inecesario, sino como una incongruencia de hipóstasis en su sistema el atender particularmente la problemática de La Esperanza; después de todo, es la historización de la filosofía lo que le permite a Hegel resolver la conciliación entre el sujeto y el objeto, entre el deseo y el mundo ${ }^{15}$. La Esperanza está puesta en la insondeable astucia de la razón como avanzada en los caminos de la realización del Espíritu, sólo que ésta Esperanza se escindió del mundo con la dominación y la barbarie modernas. Por último, tampoco parece pertinente dar cuenta de por qué los obreros han de desear un cambio, cuando éstos ya se hallan marchando en la calle; tal inquietud resultaria una futilidad por completo dispensable frente a las urgencias históricas planteadas, no por el carácter hipotético de un querer transformador del mundo, sino por el querer de aquellos agentes que ya se encontraban trabando las luchas históricas de la pujante sociedad burguesa. Es obvio que la premura y la oportunidad llevaron a Marx a escribir El Manifiesto del Partido Comunista y no una teoría de la subjetividad como condición de posibilidad de la transformación social.

La historia se encargó de cambiar las cosas de lugar y aquello que fue deslizado, por decirlo así, de contrabando en la filosofía moderna hasta Bloch, apareció entonces como carente de una elaboración sistemática que le diera sustento. ¿Por qué querría el hombre transformar el mundo a pesar de todas las adversidades? ¿De donde proviene ese impuldo de futuro? ¿Acaso es po- 
sible ocluirlo definitivamente? Bloch encontraria en la categorización de La Esperanza un terreno propicio para elaborar la problemática, precisamente, de una filosofía del querer proyectado hacia el futuro. Pero La Esperanza no es la esperanza, es decir, un simple apetito a satisfacer que como la apetencia aparece y desaparece al ritmo de una saciedad inmediata. La apetencia es el nivel más bajo del impulso humano vital, es ese que permanece siempre encerrado en sí mismo como afán egoista y que, una vez saciado, resurge permanentemente como incompletud irresoluble porque no reconoce al otro, no sabe que la satisfacción es siempre en mediación con el otro ( $c f r$. Bloch 5, caps. 9 y 10) El hombre no es propiamente un ser de apetencias: es El Ser que desea, que vuelve su anhelo hacia el exterior, hacia los otros, hacia lo otro; es, como diría Heidegger, el único ente para el cual los demás entes no son indiferentes. El deseo, a diferencia de la apetencia, imagina, construye idealmente, sueña y como tal es el primer paso para dejar atrás un presente y un pasado que se manifiestan bajo la ilusión de lo concluso.

Al mirar hacia adelante, el deseo define un pasado y un presente como perspectiva de futuro en potencia. Por ello, en la realización de su fenomenología de La Esperanza (también en su análisis de los estados de la conciencia utópica) Bloch se vió necesitado de entablar un diálogo fructífero con Freud, disputado dentro de la teoría de la interpretación de los sueños, con el propósito de desvincularlos de la función regresiva hacia el inconsciente que les es asignada dentro de la interpretación psicoanalítica. En esta visión, los sueños se reducen a una codificación represiva de lo ya-sido y son privados de todo deseo anticipador, mientras que desde la óptica de una fenomenología de la esperanza, los sueños nocturnos son una ventana hacia el futuro de lo que podrá ser realizado por la encarnación del deseo en los sueños soñados despierto o sueño diurno. No obstante, el deseo puede ser indeciso y presentarse con un carácter pasivo: se puede desear algo sin esperar que se haga realidad. El querer aúna la acción al deseo, es un avance activo y no sólo imaginario; el deseo deviene realidad únicamente si se quiere realizarlo y a la vez, sólo puede quererse lo deseado ( $c f r$. Bloch 5, caps 11 y 13). Con el querer, el deseo adquiere su verdadera fuerza y sentido radical: transformar el mundo y producir la utopía del pensamiento filosófico moderno, a saber, conciliar el pensamiento con la realidad; conciliación que, nada más y nada menos, le devolvería al hombre el señorio de su propia vida.

La Esperanza no es una cualidad íntima dependiente de la personalidad, 
no es un estado anímico de la psicología individual, es una dimensión humanamente ontológica de El Ser, pero no exclusivamente del ser del hombre, sino que también del ser de la realidad. Esta dimensión ontológicamente constitutiva de El Ser tiene lugar en la síntesis del querer y el deseo como una mediación con el mundo: "Espera, esperanza, intención hacia una posibilidad que todavía no ha llegado ha ser: no se trata sólo de un rasgo fundamental de la conciencia humana, sino, ajustado y aprehendido correctamente de una determinación fundamental dentro de la realidad objetiva en su totalidad" (Bloch 5, p. 15). La Esperanza viene a ocupar así el sitio de centro del desear de El Ser, de impulso superador de la tensión sujeto-objeto, de carencia y reconciliación con el mundo, de animación vital de la realidad y del cuerpo del hombre y de sus esfuerzos; es el alma verdaderamente humanizadora de lo humano: "La esperanza es el principio activo que Bloch considera en la base de esa tensión impulsora del sujeto a la superación de la no identidad de su objeto. (...) El problema de Bloch consiste en captar mediante el análisis de la esperanza el centro de la subjetividad (en función de la verdadera y no ilusoria o garantizada 'expectativa de espera' en el objeto)" (Zecchi 23, p. 219). La voluntad esperanzada procede de una determinación ontológica y estará presente entre los hombres siempre que su pensamiento espere algo mejor de la realidad y se resista a con-formarse al objeto o luche contra las exigencias desespiritualizadoras de los poderes de lo ya-dado, de los administradores de lo impuestamente concluso; sin embargo, La Esperanza en tanto que dimensión ontológica de la totalidad social no se objetiva a sí misma en tanto que tal, para ello son imprescindibles las utopías.

Las utopías son proyectos históricos de los hombres, las comunidades y las sociedades, que encarnan a La Esperanza, dando contenidos de posibilidad concretos a los diferentes programas de plenitud humana presentes en los más diversos quehaceres humanos, desde la arquitectura hasta la medicina, desde la música hasta la religión, pasando, por supuesto, por la política y por las formas de ordenamiento social que le coresponden ${ }^{16}$. Las utopías, por tanto, están enderezadas para interpretar el mundo y para desear algo enriquecedor de él, sin embargo, nuevamente el deseo no es querer y éste no puede abrazar cualquier deseo pues está en su "naturaleza" sólo querer lo realizable. En correspondencia, las utopías puden ser abstractas, cuando se dirigen a la construcción de un mundo mejor, olvidándose del presente y concentrando sus 
energias edificadoras en un futuro sólo deseable, nunca enraizable en algún tiempo presente, o pueden existir como utopías concretas, cuando su esfuerzo se aboca en lo fundamental a la crítica del presente desde las exigencias de transformación planteadas por un futuro no sólo deseable, sino también posible. En todo caso, las utopías no provienen de una imaginación ocurrente ni aun en el caso de las utopías abstractas, que no tienen ninguna posibilidad de realización; la utopia se construye siempre a partir de la proyección de ciertos rasgos del presente por cuanto es un deseo históricamente determinado. La relación con el presente tiene doble sentido, en primer lugar, como dicha proyección afirmativa o negativa de las características del momento y, en segundo lugar, como una sobredeterminación del presente en tanto que es visto desde y con una posibilidad de futuro (Sánchez Vázquez 21, pp. 14-20).

A pesar de Engels, que pretendió dar por finiquitada la cuestión sobre el socialismo científico y los socialismos utópicos, son la utopías concretas las que, sin renunciar a su carácter utópico, perfilan los rumbos del mundo en una intrincada articulación histórica contra los todos los poderes de lo ya-establecido y frente a todos los riesgos de lo aún-desconocido. Es ésta la gran odisea de la humanidad, el descubrir y disputar en cada caso que lo llegado a ser jamás es concluso, porque de otra manera “(...) lo ya sido subyuga lo que está en trance de ser, la acumulación de lo que ha llegado a ser cierra el paso totalmente a las categorías del futuro, del frente, del novum" "17. Los acontecimientos, por lo tanto, no contienen en sí mismos la definición completa de su significado, éste se construye según las posibilidades abiertas por ellos y según la realización de una de esas posibilidades sobre las otras como perspectiva de futuro. "La verdad que se realiza, explica Bloch, en ningún lugar es ya verdadera y es por ello utopía. El primer supuesto de la utopía (...) debe comprender también el proceso de realización de lo veradero en el que el ser y la verdad no coinciden" (Zecchi 23, p. 95). La verdad es siempre utopía porque se encuentra en proceso de realización, en ningún lugar es ya definitivamente conclusa, sin abertura al futuro. Así, de la no coincidencia entre ser y verdad proviene ese recuerdo inmemorial de los clamores de justicia, ese querer apagado por algo nuevo y reparador: La Esperanza encarnada en un sin fin de utopías de la más diversa índole, la historia mediada por esta dimensión ontológica a través de los rastros, de las realizaciones más o menos afortunadas de todas las utopías concretas creadas por el hombre. Para Bloch, en definitiva, “(...) el mundo sin 
propiedades grávidas de futuro no merece (...) ni una mirada, ni un arte, ni una ciencia. Utopía Concreta se encuentra en el horizonte de toda realidad; posibilidad real rodea, hasta lo último, las tendencias-latencias abiertas dialécticas. Estas últimas penetran archirrealistamente el movimiento inconcluso de la inconclusa materia: y movimiento es, según la profunda frase de Aristóteles, entelequia inacabada" (Bloch 5, p. 217).

Evaluando algunas de las consecuencias de la obra del filósofo de Tübingen, resulta fundamental reparar que en tanto utopía y Esperanza coinciden pero no son idénticas, la perversión de la utopía no aniquila a La Esperanza, como supone la razón desencantada del pensamiento posmoderno; igualmente, no habrá jamás utopía alguna que agote y encarne totalmente a La Esperanza, como pretendió por antonomasia la razón autoritaria del bloque socialista, además de algunos marxismos y otras tantas vanguardias de cuño político o ideológico diverso. La utopía como manifestación histórica concreta de $L a$ Esperanza no puede absorver totalmente a esta última, ni puede aniquilarla como consecuencia de su eventual perversión, pues esto supondría dar por concluídas las posibilidades de transformación de la historia o autorizar la censura y la opresión del deseo y de La Esperanza en nombre de algún modelo de humanidad autopropuesto como insuperable. La genialidad de Bloch le permitió conservar una posición nítida y crítica frente a la burocracia socialista, sin renunciar por ello al socialismo como posibilidad de utopía. Este es, sin duda, uno de los problemas que el intelecto socialista de nuestro siglo no pudo resolver con la misma claridad.

Por si fuera poco, hoy en día el "pensamiento desencantado" se presenta a sí mismo como la única forma de razonamiento adecuado a los tiempos que corren, se presenta como El Pensamiento Científico o Filosófico posible, producto de una depuración que le ha permitido liberarse de las mitificaciones desvirtuadoras del mundo. Esta modalidad de pensamiento, que estropea el apetito de la metafísica para la hartura, es la correspondiente expresión intelectual de un verdadero clima de desesperanza que, dicho sea de paso, pocos servicios presta a aquellos sectores desconsolados en los que sienta su correlato de objetividad. Una vez más, se benefician los administradores de la clausura de la realidad, los justificadores del sin-futuro de lo ya-dado. Aún cuando la "razón desencantada" se presente como un pensamiento de enorme fortaleza, en realidad, es un pensamiento alimentado por una debilidad paradójica: vi- 
goroso en el presente y desarmado para enfrentar el futuro. "La carencia de sueños hacia adelante aparece, por así decirlo, bajo un aspecto filosófico, pero ofreciendo, sin embargo, muy poca protección filosófica verdadera, no contando con las cosas que van a venir. En este escepticismo voluntario-involuntario el temor ocupa el lugar de la esperanza, y en lugar de la aprehensión del futuro como la mayor dimensión del presente (...) lo que tenemos es un antifinal (...)" (Bloch 5, p. 491).

\section{EI Antifinal como Final de la Historia}

A su llegada a Alemania Democrática, dos años después de finalizada la segunda guerra mundial, Bloch fue recibido con el ofrecimiento de ocupar la Dirección del Instituto de Filosofía de Leipzig, desde el que podria continuar con sus trabajos y contribuir a la construcción concreta de la utopía socialista. Los problemas no se hicieron esperar: a diferencia de lo que el establishment esparaba de él, sus preocupaciones no se encaminaron a contribuir a la "edificación revolucionaria de la nueva patria", sino a cuestionar que lo que ahi se estaba construyendo, que en definitiva no era La Patria -sitio entrañable del anhelo de los padres y de los antepasados-, funcionaba en contra de los obreros y del pueblo: "El pueblo trabajador no debe llegar a saber que está bien gobernado, sino él mismo debe gobernar y ello forma parte de su trabajo" (Zecchi 23, p. 49). Las ideas de Bloch animadas por su trabajo filosófico despertaron simpatías entre los estudiantes y trabajadores, y, como era de esperarse, los ataques en su contra por parte de la burocracia hicieron rauda aparición. Lo que primero fueron reticencias y después se tornó en aversiones de la nomenclatura, terminó por convertirse en denuncias de traición a la causa revolucionaria cuando Bloch inició un debate público sobre las relaciones entre el pensamiento de Marx y Hegel. Discutir la enorme herencia del pensamiento dialéctico de Hegel sobre Marx era un atrevimento contra el régimen, en la medida en que la expropiación monopólica de la lectura e interpretación de éste último habia sido convertida en patrimonio político del "centralismo democrático" comunista. Por lo demás, resulta obvio que la tentativa de dialectizar la apropiación dogmática de Marx llevaría, tarde que temprano, a cuestionar una realidad que el poder habia proclamado como estado de felicidad plena ${ }^{18}$. 
La difusión de sus ideas era motivo más que suficiente para ser tomado como sospechosa muestra de sabotaje, porque atentaba contra la inmovilidad social y política organizada y ordenada desde el Estado en "beneficio de todos". "El verdadero peligro político que Bloch representaba cuando sometía a discusión los 'principios' del marxismo 'ortodoxo', era su incidencia sobre el burocratismo stalinista del partido; se intentaba neutralizarlo encuadrando el trabajo blochiano en la órbita del idealismo y de la actividad antimarxista, para poder denunciar luego su presunto antidogmatismo como mistificación ideológica de un enemigo desenmascarado" (Zecchi 23, p. 67). De cualquier forma, Bloch fue más lejos y antes de ser definitivamente congelado promovió la realización del Congreso sobre la Libertad, en cuyo discurso de clausura afirmó la necesidad de concebir al socialismo como un espacio a construir y no como algo llegado a ser, concluso y definitivo; sólo desde esta perspectiva sería posible continuar la búsqueda de la unidad entre La Esperanza y la utopía socialista. Las palabras necias de Bloch se estrellaron en los oidos sordos de la burocracia, pero la historia les prestó buen oído y les otorgó resonancias trágicas en una larga historia de enmascaramientos que pasó por las purgas políticas, por los gulags, por las primaveras de Praga, por las revoluciones culturales y por el doloroso vacio sembrado por los acontecimentos que a finales de la década de lo ochentas sacudieron la historia política del siglo XX.

En el encuadre de significaciones que ofrece el cuerpo teórico blochiano, los acontecimientos de Europa del Este, protagonizados por Solidaridad en Polonia, el Foro Democrático en Checoslovaquia, la Perestroika en lo que era la URSS o el pueblo en Rumania, entre otros, y las guerras intestinas, el desmantelamiento de los patrimonios sociales, el caos y la rapiña política en gran escala, que se han sucedido a estos acontecimientos, presentan una dimensión que atañe al terreno de lo utópico en la que es conveniente reflexionar, siempre que, con Bloch, no estemos dipuestos a olvidarnos del futuro. La incapacidad de los paradigmas teóricos para vislumbar lo que, "como rayo en cielo sereno", tomó al mundo desprevenido, la incertidumbre delante de lo que podrá o no ser el futuro, la vertiginosa dinamización de las interacciones sociales en escala planetaria, la desmitificación de un conjunto de verdades que se consideraban como incuestionables y la hegemonía aparentemente imbatible en las más distantes latitudes de un modelo político y económico que ha ganado el nombre de neoliberal, son sin duda algunas de las determinantes fundamentales que 
pesan en lo que podria denominarse como extravio del pensamiento socialista. Particularmente, existe algo más que interesa destacar y que suele ser descuidado, se trata de La Esperanza o más bien de la desesperanza. En efecto, este pensamiento en extravío es principalmente un pensamiento desesperanzado que contempló como la utopía socialista, en el mejor de los casos, fue reducida a un puro ideal ${ }^{19}$.

El impresionante impacto de las transformaciones en el Este Europeo ha germinado en forma de un desolador desarraigo al interior mismo del pensamiento comprometido con la utopía socialista. No es para menos, los propios soviéticos acuñaron su desgracia con el sarcasmo expresivo de la broma y el aforismo en términos contundentes: “¿Cuál es la definición de socialismo?, preguntaron unos; es la primera etapa de transición al capitalismo (...), respondieron otros."; "El socialismo real es el camino más largo y sinuoso al capitalismo" (Saldivar 20, p. 152). Aún más, quienes oponiéndose en un principio a las interpretaciones simplistas sobre el rotundo triunfo del capitalismo, afirmaron que las transformaciones democráticas del bloque comunista, y principalmente la Perestroica, habían devuelto a estos países a la senda del verdadero socialismo ( $v . g r$. Semo 22), han tenido que permanecer impávidos y callados frente al maremoto de acontecimientos desatados desde entonces, ninguno de los cuales parace indicar el retorno de algún posible socialismo. Desesperanzado, el pensamiento socialista emprendió masivamente el éxodo hacia la indiferencia, hacia el escepticismo, hacia el diagnóstico posmoderno, hacia el liberalismo político y, no pocos, hacia el neoliberalismo económico. Sin Esperanza no hay mediación volitiva que guie conciencia lúcida alguna para dar cuenta de la utopía socialista, pues “(...) la razón no puede florecer sin la esperanza ni la esperanza hablar sin la razón (...)” (Bloch 5, pp. 491-2). Los puntos de vista, las teorías, tienen que estar habitados, encarnados, deseados y apropiados por la humanidad que se vale de ellos para transformarse y autocomprenderse en esta transformación. Un punto de vista deshabitado pierde toda efectividad sobre lo real, se mantiene en el vacío.

En las últimas siete décadas La Esperanza unida a la utopía socialista se mantuvo habitada por el querer de una manera relativamente patológica; el resguardo de este querer se debió a un sólido referente de objetividad: la existencia del bloque comunista y muy particularmente de la URSS, como el centro de este referente de objetividad. Se está hablando de una vieja relación 
de adecuación ideal entre la Unión Soviética y la utopía socialista, que no por pertenecer al campo de las ideas dejó de ser menos real, ni de producir consecuencias igualmente reales. En el transcurso de los 72 años que separan la revolución rusa de la caída del muro de Berlín, fue común el que la utopía socialista se fuera relacionando con lo que vino siendo su presente de una manera ilusoria, tanto más ilusoria cuanto ese presente, el llamado socialismo real, se le aparecía como la imagen realizada de su futuro. Es un sarcasmo de la historia, pero la utopía socialista se relacionó con el socialismo real como un presente que ejemplificaba su futuro de una manera poco deseable. En consecuencia, el pensamiento socialista tuvo que echar mano de múltiples recursos para construir una relación altamente contradictoria entre el socialismo real y la utopía socialista. El problema a salvar era complejo, por un lado, la Europa Comunista era la muestra más evidente de la vibilidad del marxismo-socialismo, pero por el otro, las características del socialismo real eran el mejor argumento en contra de la deseabilidad de la utopía socialista como proyecto social. Sacrificar cualquiera de los dos componentes de la contradicción tenía un alto costo, si se rescataba exclusivamente la crítica, la utopía socialista perdía el reducto intocado de objetividad en el que descansaba La Esperanza; si por el contrario, se rescataba sólo el momento positivo del socialismo real, la utopía socialista perdía toda viabilidad como un proyecto moralmente superior y, por ende, como un proyecto deseable.

Las diferentes escuelas y corrientes del pensamiento socialista elaboraron soluciones para salirle al paso a esta contradicción (cfr. Paramio 19). Los comunistas se caracterizaron en buena medida por abrazar únicamente el momento positivo de la experiencia socialista del este: "la crítica era hacerle el juego al imperialismo yanqui", como solía decirse. Para ellos, el socialismo real tenía deficiencias pero era un sistema infinitamente superior al capitalismo, en el que la igualdad en la distribución de la riqueza tornaba secundario el problema de la democracia. Los leninistas puros asumieron las desviaciones con respecto a la utopía socialista, en los términos planteados por Marx, y atribuyeron las deficiencias a que la ruptura del capitalismo se había originado en los eslabones débiles de la cadena del sistema mundial y no en los paises más desarrollados. En todo caso, las diferencias eran graduales y la superación de las mismas requería sólo de tiempo y de mucho esfuerzo. Los trotskistas, por condicionamientos que evidentemente llevan a la biografía de Trotski, 
fueron más consecuentes, la Unión Soviética y los países del este eran Estados burocráticos deformados, en los que la élite política se había transformado en una casta opresora; no obstante, la revolución social ya se había realizado, por lo que una revolución política sería suficiente para devolver a éstos Estados deformados a la senda del socialismo democrático. Los maoistas rechazaron la experiencia del este y resolvieron a través de una crítica devastadora pero poco afortunada y carente de pertinencia histórica: caracterizaron a la Unión soviética como un capitalismo de Estado.

En estas concepciones se aprecia claramente como les era indispensable salvaguardar el reducto de objetividad de la utopía socialista. Durante mucho tiempo los comunistas rechazaron prácticamente cualquier crítica; los leninistas reconocieron las anomalías, pero el desarrollo las corregiría; los trotskistas introdujeron una crítica más aguda, pero cifraron sus esperanzas en una revolución puramente política; los maoistas fueron los únicos en negar el socialismo del este, pero no se quedaron sin reducto de objetividad para la utopía socialista: la China ocupó ese lugar. La relación ilusoria con el presente, como una construcción imaginaria, permitió elaborar soluciones contradictorias en las que se mantenía a salvo la utopía. En el fondo, se advierten ciertas concesiones del pensamiento socialista ante el temor de reconocer que la utopía no había sido realizada. Temor de pararse frente al mundo confiando en La Esperanza y en la moralidad superior de su proyecto, en su deseabilidad y en una viabilidad histórica por construir, aún no demostrada.

Lo que no había realizado el intelecto socialista lo hizo la realidad, el derrumbe de los Estados comunistas le arrebató a la utopía socialista su mejor armadura, pero también la liberó de sus más pesado lastre. Es obvio que ésta es una interpretación adecuada a la incitación esperanzadora de Bloch y que todo fenómeno posee múltiples significaciones, siendo la razón la que conciente o inconcientemente elige a cuales de éllas hacer eco y a cuales pasar por alto. En cualquier caso, los sucesos de Europa del Este, aunados a la hegemonía del pensamiento neoconservador, a la vez que propiciándola, y sin olvidar las tendencias mundiales de densidad planetaria, han reconfigurado las posibilidades de futuro contenidas en el horizonte histórico de la humanidad. Sin La Esperanza, el "aún-no" de ésta y de tantas otras utopías clausura las posibilidades de transformaciones venideras; ésta preocupación no es un problema semántico, mantiene el derecho sobre el propio futuro, resgurada el principio 
-de Esperanza- de historias por construir. Nuevamente, esto es sólo una posibilidad que deberá ser habitada para ser algo más frente a quienes defienden que nuestro futuro será una simple proyección de lo ya-dado presente, para abrir los caminos frente a ese antifinal que se nos propone como el fin de la historia.

Si como Bloch afirmaba “(...) una gran filosofía expresa el pensamiento de su tiempo, [y] a su vez manifiesta aquello de que carece esa época misma, lo ya maduro para su realización en el tiempo venidero". Y si el futuro es nuestra gran carencia contemporanea y la verdad de la palabra está en aproximárnoslo, no cabe duda que la suya es una gran filosofía.

\begin{abstract}
This article intends to stimulate the study of the german philosopher's work, which is contemporary but paradoxically forgotten. It examines some key elements of Bloch's theory, its academic and political reception and the main categories that support his Philosophy of Hope. Based on his differentiation between utopia and Hope, the article finishes discussing the importance of Bloch's criticism towards Eastern Europe and making some suggestions on the analysis of the crisis of the socialist utopia.
\end{abstract}

Key-words: utopia - Hope principle - marxism - socialism - Eastern Europe.

\title{
Notas
}

1. Al respecto resulta paradigmático recordar que en su concepción de las piezas teatrales como Experiments, Bertold Brecht reescribió su Galileo Galilei, a raíz de la sombra de destrucción proyectada por la bomba atómica, para inculpar al quehacer científico por su divorcio de toda responsabilidad ética.

2. La referencia es obvia, se trata de El fin de la historia y el último hombre (Fukuyama 13).

3. El esfuerzo biográfico y de sistematización de la obra de Bloch que, al parecer, continua siendo el más autorizado, es el ya clásico estudio Ernst Bloch: utopía y esperanza en el comunismo (Zecchi 23). El único inconveniente notable de este minucioso trabajo estriba en que entre los años de 1972 y 1974 fue elaborada la última gran obra del filosofo alemán, por lo que el libro de Zecchi, públicado en Italia en su versión original en 1974, no pudo considerarla. El trabajo al que se hace referencia es Experimentum mundi (Bloch 4).

4. “(...) En este libro se emprende, por eso, con especial atención el ensayo de llevar 
filosofía a la esperanza (...)" (Bloch 5, p. 15). La edición en castellano respeta la versión original de la obra que fue publicada en tres volúmenes, aparecidos en Berlín durante los siguientes años: I -1954, II -1955 y III -1959; en este último año la obra fue editada en Frankfurt en un formato de dos tomos.

5. No es gratuito que desde entonces sea tan fácil, aunque poco atinado, sostener que “(...) el tal espíritu resulta ser una máquina antropofágica a mayor y a menor, hacia adentro y hacia afuera (...)" (Juanes 16, p. 39).

6. No hay que olvidar que Bloch es un gran conocedor de la obra de Hegel, uno de los pocos marxistas a los que les puede ser reconocida esta condición. Esto quedó manifesto en su conocido estudio: Sujeto-objeto. El pensamiento de Hegel, cuya versión original fue publicada en 1949 y corregida, aumentada y reeditada en 1959 (Bloch 9).

7. La cita proviene de la obra de Bloch que posiblemente más impacto produjo en el pensamiento cristiano, a saber, Thomas Münzer, teólogo da Revolução, cuya publicación original data de 1921 (Bloch 10, pp. 206-207).

8. Ya en su primera obra L'esprit de l'útopie Bloch se adentraba en el poco explorado terreno de la indetermionación de la posibilidad (Bloch 11, pp. 229-275). El año de edición original es 1918, com posteriores modificaciones y revisiones en 1923 y 1964.

9. Al respecto, resulta altamente sintomática la opinión de otro pensador alemán como Habermas respecto a la obra de Bloch ( $c f r$. Habermas 15).

10. Pérez del Corral intituló su estudio sobre el filósofo alemán El marxismo cálido: Ernst Bloch. El título, agudamente elegido, corrió con fortuna y se tradicionalizó como una referencia al tipo de marxismo blochiano.

11. Un registro de la recepción del pensamiento de Bloch por la ortodoxia del marxismo comunista Staliniano se encuentra meticulosamente detallado en la obra de Stefano Zecchi (Zechhi 23, pp. 21-69).

12. Bloch construye una función aticipadora de los sueños a través de la conexión entre el sueño nocturno (Nachttraum) y los sueños soñados despierto o sueño diurno (Tagtraum). Esta interpretación tiene implicaciones de importancia para la categoria freudiana de "inconsciente" y para la teoria de la interpretación de los sueños del próprio Freud, que serán comentadas más adelente.

13. "El concepto es el organon del pensamiento y a la vez el muro que le separa de lo que piensa; por ello niega esse anhelo. La filosofía no puede ni evadir tal negación ni plegarse ante ella. Sólo la filosofía puede y debe emprender el esfuerzo de superar el concepto por medio del concepto" (Adorno 1, pp. 23-24).

14. V. Gr. "El proletariado es revolucionario frente a la burguesía, porque habiendo surgido sobre la base de la gran industria, aspira a despojar a la producción de su carácter capitalista, que la burguesía quiere perpetuar" (Marx 17, p. 21). 
15. Para hacer justicia a Hegel en estos menesteres, nada como el propio Bloch: “(...) no hay otro libro que en su estructura conceptual esté recorido al mismo tiempo por sectores tan completos de análisis sobre las pasiones como la Fenomenología del Espíritu" (Bloch 5, p. 79).

16. Bloch efectua un análisis minucioso del conjunto de utopías que se han presentado a la humanidad en los distintos campos de la actividad social: arte, medicina, arquitectura, etc. (cfr. Bloch 6).

17. Este juicio está orientado a caracterizar los límites de la dialéctica de la historia en Hegel. En mi opinión, la apreciación es certera en lo general, pero no hace justicia a Hegel (Bloch 5). Respecto al novum, para Bloch eran tres las categorías centrales del proceso dialéctico: la frontera, el novum y la materia. "El novum es la posibilidad real de lo todavía-no-consciente, de lo no-llegado-a-ser-todavía, con el acento en el novum (reino de la libertad) cuando es activada la tendencia en esta dirección" (Bloch 7, p. 496).

18. Recuérdese, por ejemplo, que Stalin abolió por decreto las clases sociales inaugurando pomposamente la entrada del socialismo al comunismo ( $c f r$. Balibar 3)

19. Ideal en el sentido adorniano, es decir, como un concepto que lleva implícita la imposibilidad de ser ( $c f r$. Adorno y Horkheimer 2).

\section{Referencias Bibliográficas}

1. ADORNO, Theodor W., Dialéctica Negativa, Barcelona, Taurus, 1989.

2. ADORNO, Theodor W. e HORKHEIMER, Max, Sociológica, Barcelona, Taurus, 1987.

3. BALIBAR, Etiene, La dictadura del proletariado, México, Siglo XXI, 1985.

4. BLOCH, Ernst, Experimentum mundi, Frankfurt, Suhrkamp, 1975.

5. . El principio de esperanza, Madrid, Aguilar, 1977, Tomo I. 
6. El principio de esperanza, Madrid, Aguilar, 1977, Tomo II.

7. El El principio de esperanza, Madrid, Aguilar, 1977, Tomo III.

8. L_' L'athéisme dans le Christianisme, Paris, 1978.

9. . Sujeto-objeto. El pensamiento de Hegel, México, Fondo de Cultura Económica, 1978.

10. . Thomas Münzer, teólogo da Revolução, Rio de Janeiro, Tempo Brasileiro, 1973.

11. . L'esprit de l'útopie, Paris, Gallimard, 1977.

12. . Politische Messungen, Pestzeit, Vormärz, Frankfurt, Suhrkamp, 1970.

13. FUKUYAMA, Francis, El fin de la historia y el último hombre, México, Planeta, 1992.

14. GRAMSCI, Antonio, Notas sobre Maquiavelo, sobre politica y sobre el Estado moderno, México, Juan Pablos, 1975.

15. HABERMAS, Jürgen, Perfiles filosófico-políticos, Barcelona, Taurus, 1986.

16. JUANÉS, Jorge, Los caprichos de occidente, Puebla, Universidad Autónoma de Puebla, 1990.

17. MARX, Carlos, Crítica al Programa de Gotha, Moscú, Progreso, 1985.

18. OPOLKA, Uwe, "Heritage et réalisme - Ernst Bloch dans le débat sur le expressionisme (1737-1738)", en Raulet, Gérard (dir.), Utopiemarxisme selon Ernst Bloch: un système de l'inconstructible, Paris, Payot, 1976.

19. PARAMIO, Ludolfo, Tras el diluvio. La izquierda ante el fin de siglo, México, Siglo XXI, 1990.

20. SALDIVAR, Américo, El ocaso del socialismo, México, Siglo XXI, 1990.

21. SÁNCHEZ VÁZQUEZ, Adolfo, Del socialismo científico al socialismo 
utópico, México, Era, 1987.

22. SEMO, Enrique, “1989: Umbral de una Época”, Conferencia magistral dictada en el coloquio "El Futuro del Socialismo”, Ciudad de México, 1991.

23. ZECCHI, Stefano, Ernst Bloch: utopía y esperanza en el comunismo, Barcelona, Península, 1978. 